\title{
Cytostatic effects of plant essential oils on human skin and lung cells
}

\author{
CHANGHWAN AHN ${ }^{1}$, JAE-HWAN LEE ${ }^{1}$, MI-JIN PARK ${ }^{2}$, JAE-WOO KIM ${ }^{2}$, \\ JIYOON YANG ${ }^{2}$, YEONG-MIN YOO ${ }^{1}$ and EUI-BAE JEUNG ${ }^{1}$
}

\author{
${ }^{1}$ Laboratory of Veterinary Biochemistry and Molecular Biology, College of Veterinary Medicine, \\ Chungbuk National University, Cheongju, Chungbuk 28644; ${ }^{2}$ Division of Wood Chemistry and Microbiology, \\ Department of Forest Products, National Institute of Forest Science, Seoul 02455, Republic of Korea
}

Received March 16, 2019; Accepted October 7, 2019

DOI: $10.3892 /$ etm.2020.8460

\begin{abstract}
Essential oils are volatile compounds extracted from various plants by distillation, hydrodiffusion or compression. In recent years, the use of essential oils has gained popularity. Many pharmaceutical, cosmetic, sanitary, food industry and agriculture studies have revealed that essential oils exert antibacterial, antiviral, antifungal, antiparasitic, insecticidal, anticancer, neuroprotective, psychophysiological and anti-aging effects. Despite their reported uses, recent studies of eukaryotic cells have demonstrated that essential oils exert prooxidant and cytotoxic effects. Therefore, for the effective clinical use of essential oils, an evaluation of their cytotoxicity and the identification of the mechanisms affecting cell viability are required. To evaluate cytotoxicity, the present study determined the $\mathrm{IC}_{50}$ values of 15 essential oils provided by the Korea Forest Research Institute (Pinus densiflora for. multicaulis Uyeki, Trifolium repens, Ligularia fischeri, Abies nephrolepis, Illicium anisatum, Zanthoxylum coreanum, Abies koreana, Lindera obtusiloba, Chamaecyparis obtuse, Pinus densiflora, Magnolia kobus, Picea koraiensis, Picea abies, Abies holophylla and Platycladus orientalis). Their effect was then assessed in human lung cells (A549) and human skin cells (Detroit 551) by performing cell counting kit-8 assays. To identify the mechanism associated with each oil's cytotoxicity, expressions of cytotoxicity-associated marker genes (cyclin A, cyclin B, cyclin D and cyclin E) involved in the cell cycle and caspase-3 (involved in cell death) were examined by performing reverse transcription-quantitative PCR and western blotting. In conclusion, plant essential oils can be used as a good source of medicine. However, without examining the safety of essential oils, they cannot be used in clinics. The results included
\end{abstract}

Correspondence to: Professor Eui-Bae Jeung, Laboratory of Veterinary Biochemistry and Molecular Biology, College of Veterinary Medicine, Chungbuk National University, 1 Chungdaero, Cheongju, Chungbuk 28644, Republic of Korea

E-mail: ebjeung@chungbuk.ac.kr

Key words: essential oil, cell death, cytotoxicity, cell cycle estimates of the degree of cytotoxicity and the mechanism of cell death for each oil. It is expected that the data obtained from the current study will form guidelines for the clinically appropriate and safe use of these tested essential oils.

\section{Introduction}

Essential oil is a mixture of highly complex, naturally occurring, volatile aroma compounds synthesized in medicinal and aromatic plants as secondary metabolites (1). Essential oils can be extracted from leaves, flowers, and stems by solvent extraction, hydrodistillation, or steam distillation (2). In recent years, there has been increasing interest worldwide in the use of alternative/herbal medicines for the prevention and treatment of various illnesses (3). Essential oils are widely used in pharmaceutical, cosmetic, sanitary, food industry, and agriculture for their antibacterial, antiviral, antifungal, antiparasitic, insecticidal, anticancer, neuroprotective, psychophysiological, and anti-aging activities (1). However, much of the research into essential oils is still in its early state, and a systematic and rigorous approach to the study of biological activities of potential phytotherapeutics has only been initiated in recent decades. This is particularly true regarding the cytotoxic effects of phytocomplexes (4). Because of the increasing popularity of essential oils and the prevalence of essential oil-based self-care practices targeting a wide variety of ailments in the United States, healthcare professionals need to be prepared to address concerns about the agents' safety and efficacy. Thorough literature evaluation of a purported therapeutic requires the ability to discern the quality of an oil, the safety of its administration, and the validity of its declared use (5). However, there is considerable anecdotal information about the biological activity of essential oils, and much of that information has not been substantiated by scientific or clinical evidence (6). A recent study has shown that, in eukaryotic cells, essential oils can act as prooxidants affecting inner cell membranes and organelles such as mitochondria. Depending on the type and concentration, essential oils can exhibit cytotoxic effects on living cells, but they are usually non-genotoxic (7).

The cell cycle is divided into discrete phases: G1 (gap 1) is the interval or gap between mitosis (M phase) and DNA synthesis (S phase). During G1, the cell is subject to stimulation 
by extracellular mitogens and growth factors, and, in response to these stimuli, the cell passes through G1 and proceeds with DNA synthesis in the S phase (8). G2 (gap 2) is the interval between the completion of DNA synthesis and mitosis, and the $\mathrm{M}$ phase is marked by the generation of bipolar mitotic spindles, segregation of sister chromatids, and cell division (8). The G1/S and G2/M cell-cycle checkpoints maintain genomic stability in eukaryotes in response to genotoxic stress (9). The balance between cyclin-dependent protein kinase (CDK) activation and inactivation determines whether cells proceed through G1 into the $\mathrm{S}$ phase, as well as from $\mathrm{G} 2$ to $\mathrm{M}$, through regulatory mechanisms that are conserved in more complex eukaryotes (10).

The formation of cyclin D/CDK complexes results in phosphorylation and activation of the CDKs (11). The critical role for CDK4 and CDK6 during cell-cycle progression is to phosphorylate the tumor suppressor $\mathrm{pRb}$, which consequently permits the transition from G1 to the S phase (12). As the cell progresses through late $\mathrm{G} 1$, there is increased expression of cyclin $\mathrm{E}$, and cyclin $\mathrm{E} / \mathrm{CDK} 2$ complexes are required for the transition from $\mathrm{G} 1$ to the $\mathrm{S}$ phase. Increased expression of cyclin A occurs at the G1/S transition and persists through the $\mathrm{S}$ phase. With the binding of cyclin A to CDK2, DNA synthesis proceeds. In the latter part of the $S$ phase, cyclin $A$ associates with CDK1. A checkpoint in G2 responds to the presence of DNA damage or incomplete DNA synthesis; as a consequence, progression into mitosis is delayed allowing DNA repair or the cycle is aborted. Increased levels of cyclins $\mathrm{A}$ and $\mathrm{B}$ complexed with CDK1 propel the cell through mitosis (n.b., historically, CDK1 was referred to as cdc2) (11). Cyclin $\mathrm{A} / \mathrm{CDK} 2$ complexes are active from the onset of the $\mathrm{S}$ phase through the $\mathrm{G} 2$ phase and into the early $\mathrm{M}$ phase, at which point the complex is inactivated by cyclin A degradation (12). The active cyclin B1/CDK1 complex first appears at the centrosome, suggesting that the centrosome may facilitate the activation of mitotic regulators that are required for the commitment of cells to proceed to mitosis (13).

Interleukin 1-converting enzyme-like proteases (caspases) are crucial components of cell-death pathways (14). Caspase-3 normally exists in the cytosolic fraction of cells as an inactive precursor that is activated proteolytically when cells are signaled to undergo apoptosis (15). The activation of apoptosis occurs in two stages: First, cytosolic caspase-3 is cleaved and activated in a reaction that is triggered by cytochrome c released from mitochondria; and second, the activated caspase-3 interacts with other cytosolic proteins to generate DNA fragmentation when it is added to isolated nuclei $(16,17)$. Thus, caspase-3 is essential for certain processes associated with the dismantling of the cell and the formation of apoptotic bodies, but it may also function before, or at the stage when, the commitment to loss of cell viability is made (18).

In this study, to determine the appropriateness of using several plant essential oils clinically, we identified the $\mathrm{IC}_{50}$ values of essential oils extracted from Pinus densiflora for. multicaulis Uyeki, Trifolium repens, Ligularia fischeri, Abies nephrolepis, Illicium anisatum, Zanthoxylum coreanum, Abies koreana, Lindera obtusiloba, Chamaecyparis obtuse, Pinus densiflora, Magnolia kobus, Picea koraiensis, Picea abies, Abies holophylla, and Platycladus orientalis in human lung (A549) and human skin (Detroit 551) cells. In addition, the mechanism of cytotoxicity of each of the essential oils was determined by examining changes in the gene and protein expressions of four cell-cycle markers (cyclin A, cyclin B, cyclin D, and cyclin E) and one cell-death marker (caspase-3).

\section{Materials and methods}

Essential oil extraction from plants. The plants come from National Experimental Forest in Pocheon city, Gyeonggi-do and Seogwipo city, JeJu-do, Republic of Korea. The sampling was performed with the permission of operations officer of experimental forest of National Institute of Forest Science for the purpose of experiments. The threatened/endangered/near threatened species such as Abies koreana, Chamaecyparis obtuse, Abies holophylla, Platycladus orientalis samples came from byproduct with the cutback. All the threatened/endangered/near threatened species sample was obtained non-lethal, sustainable, responsible collecting which is following International Union for Conservation of Nature Species Survival Commission recommendations with the government official from National Institute of Forest Science of Korea. Taxonomical identifications were established by the ecologist Dr. Jae-Min Chung from Korean National Institute of Forest and the voucher specimens was preserved in Korea National Arboretum.

Hydrodistillation was used for extracting essential oils from plant samples. The essential oil from one kilogram of freshly cut plant leaves is obtained by steam distillation using a manufactured apparatus with a condenser at $105^{\circ} \mathrm{C}$. Distillation (EAMS 9501; Misung Scientific Co. Ltd.) was continued for $7 \mathrm{~h}$ at $100^{\circ} \mathrm{C}$ and the volatile compounds containing the water-soluble fraction were allowed to settle for $20 \mathrm{~min}$. The extracted essential oils were added $\mathrm{Na}_{2} \mathrm{SO}_{4}(98.5 \%$; $\mathrm{SAMCHUN})$ to subduct water from essential oil. The essential oil layer was separated and finally purified using a microfilter (pore size, $0.45 \mu \mathrm{m}$ ) and the water vapor distillation method.

Cell proliferation assay. Human lung (A549) and human skin (Detroit 551) cells were purchased from the Korean Cell Line Bank (KCLB). Cells were seeded at a density of $0.5 \times 10^{3}$ cells per well in 96-well plate and $100 \mu \mathrm{l}$ of media used for cell culture which are DMEM high-glucose media (Biowest) supplemented with penicillinstreptomycin solution (Biowest), Plasmocin ${ }^{\mathrm{TM}}$ prophylactic (Biowest), and fetal bovine serum. Cells were incubated in a $\mathrm{CO}_{2}$ atmosphere at $37^{\circ} \mathrm{C}$ for $24 \mathrm{~h}$ prior to treating with an essential oil. The plant essential oils were prepared in four concentrations $10^{-8}, 10^{-6}, 10^{-4}$, and $10^{-2} \%$ and distilled water as a vehicle (specimen volume/media volume). After $24 \mathrm{~h}$, the cells are treated with diluted plant essential oil as indicated and incubated for $24 \mathrm{~h}$. Subsequently, the plant essential oil and the medium treating the cells were removed and the cells washed with PBS solution (Welgene). EZ-Cytox enhanced cell viability assay reagent (DoGenBio) at the recommended concentration was then placed in each well. One hour later, the absorbance value at $450 \mathrm{~nm}$ was measured with an Epoch microplate spectrophotometer (BioTek). Cell viability (\%) was determined by comparing optical density (OD) values via the formula $\mathrm{OD}_{\text {sample }} / \mathrm{OD}_{\text {control }} \mathrm{x} 100$ for each concentration range. A cell survival curve was calculated from the obtained values, and the oil's $\mathrm{IC}_{50}$ value was established. After conducting 
the CCK assay, the same procedure was repeated with plant essential oils that were diluted to concentrations of $10^{-6}, 10^{-5}$, $10^{-4}, 10^{-3}, 10^{-2}$. All experiment was replicated four times. The $\mathrm{IC}_{50}$ values were calculated with Graph Pad Prism (v.5.0; GraphPad Software) with nonlinear regression (curve fit) in the $95 \%$ confidence interval.

RNA extraction. Cells were seeded in 6-well plates at a density of $0.3 \times 10^{4}$ cells per well and incubated at $37^{\circ} \mathrm{C}$ in $5 \% \mathrm{CO}_{2}$ atmosphere. Plant essential oils in DMEM high-glucose media (Biowest) were prepared in three concentrations: $\mathrm{IC}_{50}$ from the CCK assay, 10 times more than the $\mathrm{IC}_{50}$, and 10 times less than the $\mathrm{IC}_{50}$. When cell confluency was $70 \%$, the cells were treated with the appropriate concentration of plant essential oil. Harvesting of cells and RNA extraction were accomplished by using TRI reagent (Invitrogen) at $24 \mathrm{~h}$ after plant essential oil treatment. The purity and concentration of the extracted RNA were measured by using an Epoch microplate spectrophotometer (BioTek).

Synthesis of $c D N A$. The extracted RNA was synthesized by reverse transcription (RT). The concentration of RNA was titrated to $1 \mu \mathrm{g} / \mu \mathrm{l}$ and DEPC-treated water was added to adjust the total volume to $10.5 \mu \mathrm{l}$. The mixture contained Moloney murine leukemia virus reverse transcriptase (Invitrogen), Ribonuclease inhibitor (Invitrogen), random primers (6-mers; TaKaRa), 100 mM DTT (Invitrogen), dNTP, and 5x first-strand buffer. The reaction mixture was incubated at $37^{\circ} \mathrm{C}$ for $60 \mathrm{~min}$. After incubation, the cells were incubated further at $95^{\circ} \mathrm{C}$ for $5 \mathrm{~min}$ for inactivation of the enzyme. After cooling for $5 \mathrm{~min}$ on ice, the cDNA was stored at $-20^{\circ} \mathrm{C}$ prior to use.

Quantitative PCR. For qPCR, a master mix of the following reaction components was prepared: cDNA sample $(2 \mu \mathrm{l})$, $0.25 \mu 1$ 50x ROX dye, $6.25 \mu 1$ 2x prime Q-mastermix SYBR (GeNetBio), 10 pM forward and reverse primer. QPCR was performed using a 7300 RT-PCR system (Applied Biosystems), and the procedure sequence was as follows: cDNA denatured at $95^{\circ} \mathrm{C}$ for $30 \mathrm{sec}$ and annealed at $58^{\circ} \mathrm{C}$ for $30 \mathrm{sec}$, elongation performed at $72^{\circ} \mathrm{C}$ for $30 \mathrm{sec}$, and the whole cycle is repeated 40 times. The degree of gene expression was determined by using RQ software (Applied Biosystems). The primer sequences used are as follows: 5'-CATACTCCACAG CACCTGGTTA-3' (forward) and 5'-CTGTTGCCACCTTTC GGTTA-3' (reverse) for caspase-3; 5'-TACTTTCTGCATCAG CAGCC-3' (forward) and 5'-TGATTCAGGCCAGCTTTG TC-3' (reverse) for cyclin A; 5'-CTTTGCACTTCCTTCGGA GA-3' (forward) and 5'-GTAGAGTTGGTGTCCATTCAC C-3' (reverse) for cyclin B; 5'-CCTCGGTGTCCTACTTCA-3' (forward) and 5'-CTCCTCGCACTTCTGTTC-3' (reverse) for cyclin D; and 5'-GGTTTCAGGGRATCAGTGGT-3' (forward) and 5'-TTTCTTTGCTCGGGGCTTTG-3' (reverse) for cyclin E. The primer sequence for Rn18s, 5'-CTCAACACGGGA AACCTCAC-3' (forward) and 5'-CGCTCCACCAACTAA GAACG-3' (reverse), was used as the primer for the control group. All primers were obtained from Macrogen.

Western blot analysis. Proteins were extracted using Pro-prep (InTron Inc.) according to the manufacturer's instructions. Proteins (30 $\mu \mathrm{g}$ per lane) were separated on a $10 \%$ SDS-PAGE gel and transferred to a polyvinylidene fluoride transfer membrane (Perkin Elmer Co.) in a TransBlot Cell (TE-22; Hoefer Co.) according to the manufacturer's instructions. The resulting blot was blocked with TBS-T containing 5\% skimmed milk for $60 \mathrm{~min}$, then incubated with primary antibody: Caspase-3 (mouse monoclonal, 1:500, cat. no. 9665), Cyclin A2 (mouse monoclonal, 1:500, cat. no. 4656), Cyclin B1 (rabbit polyclonal, 1:500, cat. no. 4138), Cyclin D1 (rabbit monoclonal, 1:500, cat. no. 2978), Cyclin E1 (mouse monoclonal, 1:500, cat. no. 4129), or $\beta$-actin (rabbit monoclonal, 1:1,000, cat. no. 4970; all purchased from Cell Signaling Technology). After washing in buffer, the membranes were incubated with the appropriate horseradish peroxidase-conjugated secondary antibodies (anti-goat, 1:2,000 or anti-mouse, 1:4,000; Santa Cruz) for $1 \mathrm{~h}$ at room temperature. Next, the blots were developed by incubation in ECL chemiluminescence reagent (Santa Cruz) and subsequently exposed to the GeneGnome Bioimaging System (Syngene) for development, after which images were captured by using the GENESys software (Syngene). Signal specificity was confirmed by blotting in the absence of primary antibody, and bands were normalized to $\beta$-actin immunoreactive bands visualized on the same membrane after stripping. The density of each band was measured using the NIH ImageJ software.

Statistical analysis. All data were analyzed by applying nonparametric one-way analysis of variance followed by Turkey's test for multiple comparisons. All experiments consisted of three separate trials. Statistical analysis was performed by using Graph Pad Prism (GraphPad Software).

\section{Results}

Two-step identification of $I C_{50}$ value of each essential oil. CCK-8 assays were used to determine $\mathrm{IC}_{50}$ values of 15 essential oils. To determine the test concentration, the cells were treated initially with four concentrations, followed by testing of further concentrations in CCK-8 assays. The $\mathrm{IC}_{50}$ values of the 15 essential oils are presented in Figs. 1 and 2 . For the initial testing of concentrations of the essential oils (i.e., $10^{-8}, 10^{-6}, 10^{-4}, 10^{-2}, 1 \%$ ), the $\mathrm{IC}_{50}$ values (\%) were determined to be 0.2001 (Pinus densiflora for. multicaulis Uyeki), 0.0521 (Trifolium repens), 0.6011 (Ligularia fischeri), 0.1127 (Abies nephrolepis), 0.3551 (Illicium anisatum), 0.0391 (Zanthoxylum coreanum), 0.0946 (Abies koreana), 0.8551 (Lindera obtusiloba), 0.0339 (Chamaecyparis obtusa), 0.0065 (Pinus densiflora), 0.553 (Magnolia kobus), 0.0526 (Picea koraiensis), 0.0364 (Picea abies), 0.0473 (Abies holophylla), and 0.0987 (Platycladus orientalis) in A549 cells and as 0.3321 (Pinus densiflora for. multicaulis Uyeki), 0.2869 (Trifolium repens), 0.4013 (Ligularia fischeri), 1.037 (Abies nephrolepis), 0.3440 (Illicium anisatum), 0.4661 (Zanthoxylum coreanum), 1.190 (Abies koreana), 0.8859 (Lindera obtusiloba), 0.1246 (Chamaecyparis obtusa), 0.2863 (Pinus densiflora), 0.0748 (Magnolia kobus), 0.0460 (Picea koraiensis), 0.0274 (Picea abies), 0.1031 (Abies holophylla), 0.0165 (Platycladus orientalis) in Detroit 551 cells.

For the testing of further subdivisions of the concentrations of the essential oils (i.e., $10^{-5}, 10^{-4}, 10^{-3}, 10^{-2}, 1 \%$ ), the $\mathrm{IC}_{50}$ values (\%) were determined to be 0.1788 (Pinus densiflora for. multicaulis Uyeki), 0.0420 (Trifolium repens), 0.4609 (Ligularia fischeri), 0.0979 (Abies nephrolepis), 0.0398 (Illicium anisatum), 

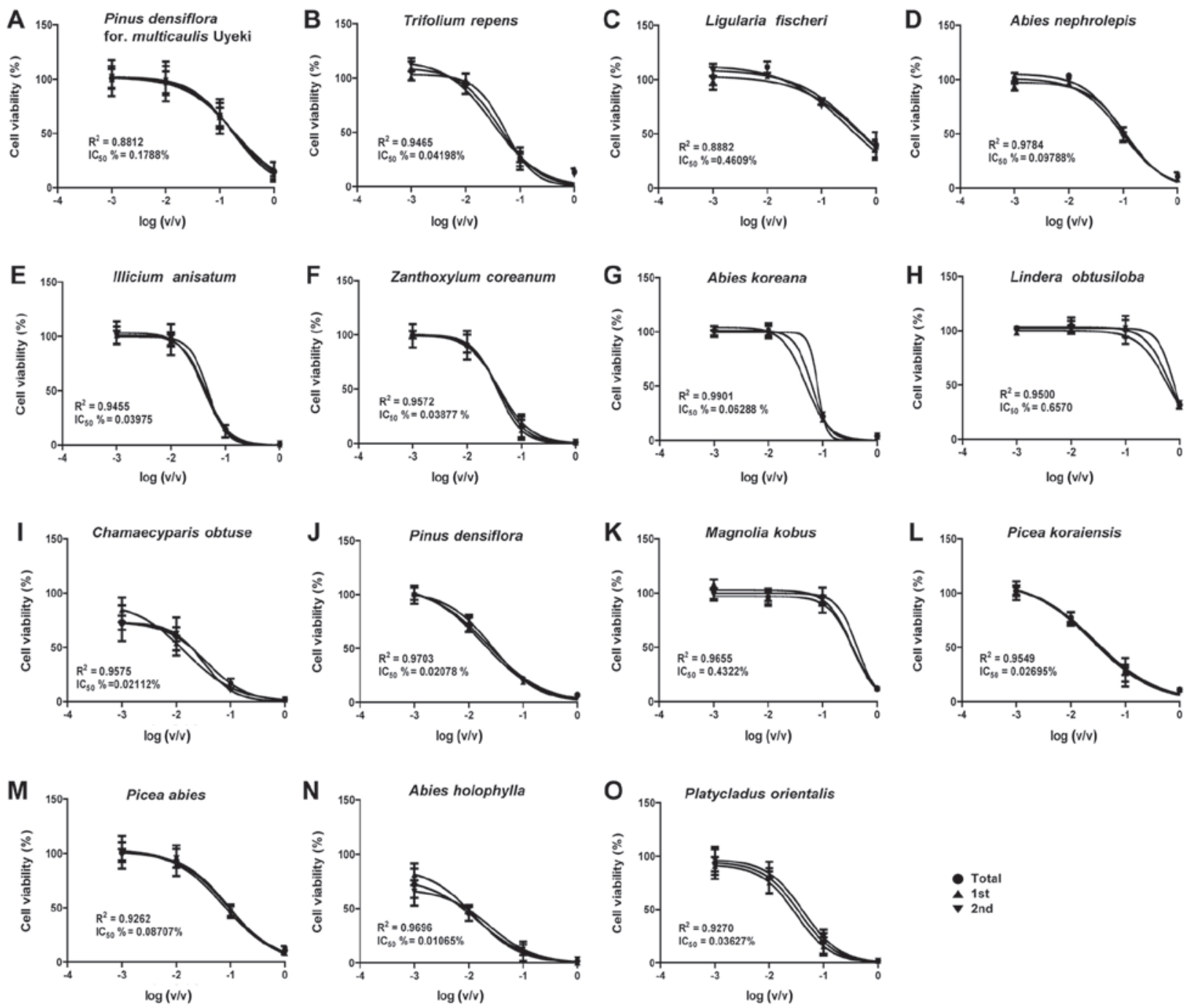

Figure 1. A549 cell survival curves for the determination of essential oil $\mathrm{IC}_{50}$ values. After cells were treated with an essential oil, the OD was measured by performing a cell counting kit- 8 assay. Cell viability was determined using the following formula: $\mathrm{OD}_{\text {sample }} / \mathrm{OD}_{\text {control }} \mathrm{x} 100(\%)$, after which the $\mathrm{IC}_{50}$ value was determined through the obtained survival curve. (A) Pinus densiflora for. multicaulis Uyeki, (B) Trifolium repens, (C) Ligularia fischeri, (D) Abies nephrolepis, (E) Illicium anisatum, (F) Zanthoxylum coreanum, (G) Abies koreana, (H) Lindera obtusiloba, (I) Chamaecyparis obtuse, (J) Pinus densiflora, (K) Magnolia kobus, (L) Picea koraiensis, (M) Picea abies, (N) Abies holophylla, (O) Platycladus orientalis. OD, optical density.

0.0388 (Zanthoxylum coreanum), 0.0629 (Abies koreana), 0.6570 (Lindera obtusiloba), 0.0211 (Chamaecyparis obtusa), 0.0207 (Pinus densiflora), 0.4322 (Magnolia kobus), 0.0270 (Picea koraiensis), 0.0871 (Picea abies), 0.0107 (Abies holophylla), and 0.0363 (Platycladus orientalis) in A549 cells (Table I) and as 0.3112 (Pinus densiflora for. multicaulis Uyeki), 0.4699 (Trifolium repens), 0.2497 (Ligularia fischeri), 0.1852 (Abies nephrolepis), 0.4954 (Illicium anisatum), 0.1736 (Zanthoxylum coreanum), 0.1757 (Abies koreana), 0.6819 (Lindera obtusiloba), 0.2663 (Chamaecyparis obtusa), 0.3411 (Pinus densiflora), 0.0475 (Magnolia kobus), 0.0188 (Picea koraiensis), 0.0102 (Picea abies), 0.1164 (Abies holophylla), 0.1797 (Platycladus orientalis) in Detroit 551 cells (Table II).

Expression of caspase-3 gene affected by plant essential oils. Expression levels of the caspase-3 gene, an apoptosis marker gene, were determined by performing reverse transcription-quantitative PCR (RT-qPCR) in essential oil-treated cell lines (Fig. 3). In the A549 human lung cell line, the expression level of caspase- 3 was decreased by high concentrations of all of the tested essential oils. However, in the Detroit 551 human skin cell line, the expression level of caspase-3 was increased only in high concentrations of Zanthoxylum coreanum and Ligularia fischeri, while it was decreased in high concentrations of Lindera obtusiloba, Abies koreana, and Abies nephrolepis.

The expression levels of caspase-3 protein, an apoptosis marker, in the A549 and Detroit 551 cells were determined by analyzing western blots (Fig. 4). In the Detroit 551 cells, the expression level of caspase-3 protein was increased at concentrations near the $\mathrm{IC}_{50}$ values.

Expressions of cyclin A, cyclin B, cyclin D, and cyclin E affected by plant essential oils. The gene expression levels of cyclin A, cyclin B, cyclin D, and cyclin E in the A549 and Detroit 551 cell lines after treatment with different concentrations of the essential oils tested in this study are shown in Figs. 3 and 4.

For all the tested essential oils, the gene expression of cyclin A, a cell-cycle regulation marker, showed concentration-dependent decreases in A549 cells. The expression of cyclin B decreased after treatment with all oils except Ligularia fischeri in which the 

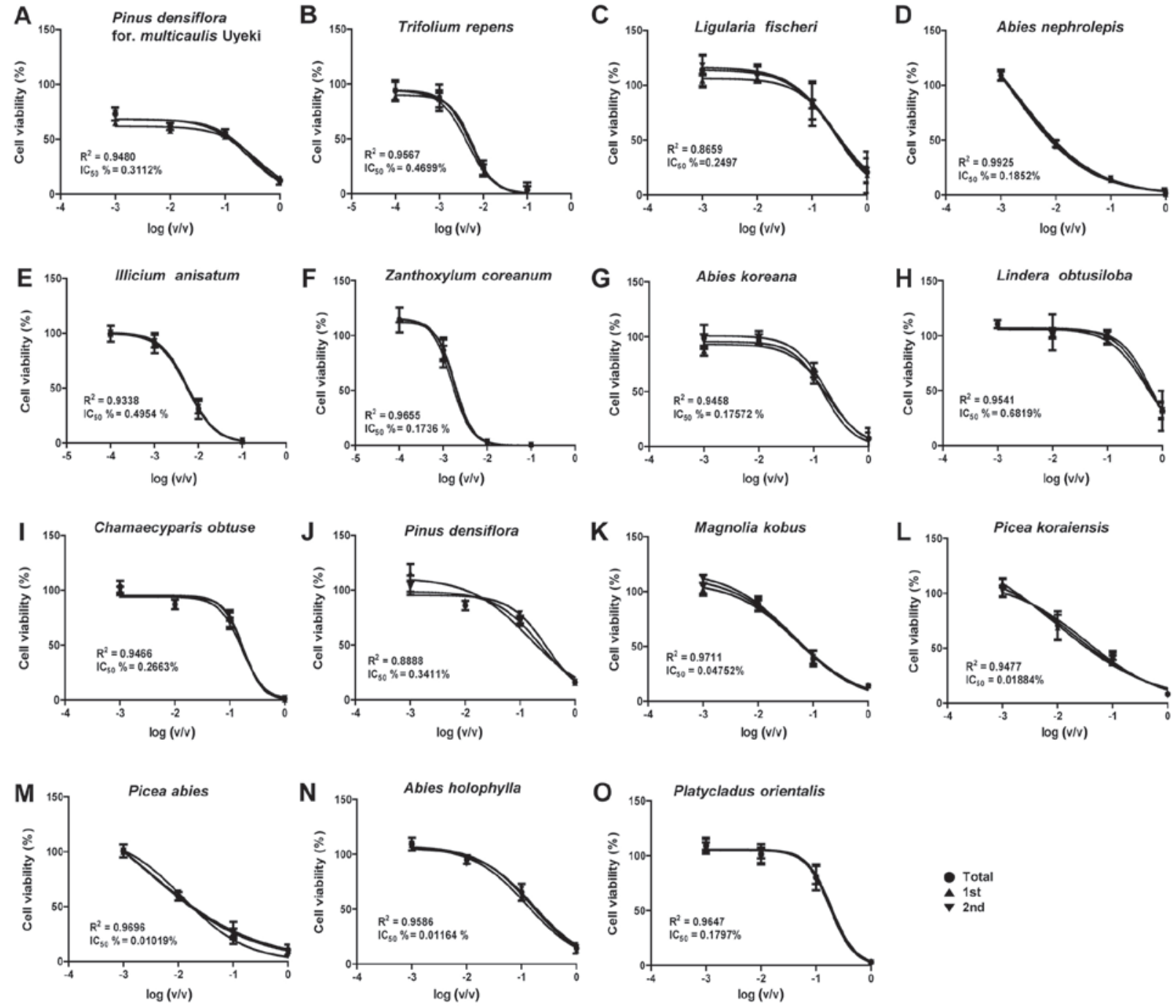

Figure 2. Detroit 551 cell survival curves for the determination of essential oil $\mathrm{IC}_{50}$ values. After the cells were treated with an essential oil, Cell viability was determined using the following formula: $\mathrm{OD}_{\text {sample }} / \mathrm{OD}_{\text {control }} \times 100(\%)$, after which the $\mathrm{IC}_{50}$ value was determined through the obtained survival curve. (A) Pinus densiflora for.multicaulis Uyeki,(B) Trifolium repens, (C) Ligularia fischeri,(D) Abies nephrolepis,(E) Illicium anisatum,(F)Zanthoxylum coreanum, (G) Abies koreana, (H) Lindera obtusiloba, (I) Chamaecyparis obtuse, (J) Pinus densiflora, (K) Magnolia kobus, (L) Picea koraiensis, (M) Picea abies, (N) Abies holophylla, (O) Platycladus orientalis. OD, optical density.

expression level of cyclin B increased in A549 cells. The cyclin D expression in A549 cells showed decreases when they were treated with Zanthoxylum coreanum and Abies koreana but showed increases with Ligularia fischeri and Abies nephrolepis treatment. Treatment with the essential oil of Lindera obtusiloba produced no tendency for change in cyclin D expression in A549 cells. Expressions of cyclin E in A549 cells slightly decreased in Ligularia fischeri and Abies koreana. Similarly, the expressions of cyclin E in A549 cells showed no tendency for change after treatment with essential oils of Lindera obtusiloba,Zanthoxylum coreanum, and Abies nephrolepis.

In Detroit 551 cells, the gene expression of cyclin A decreased in all samples except Ligularia fischeri in which the expression of cyclin A increased. The expression of cyclin B in Detroit 551 cells showed a decrease with Lindera obtusiloba treatment but showed increases after Ligularia fischeri, Abies koreana, and Abies nephrolepis treatment. There was no tendency for change in cyclin B expression in Detroit 551 cells after treatment with Zanthoxylum coreanum. The expression levels of cyclin D in Detroit 551 cells decreased after
Lindera obtusiloba and Abies koreana treatment but increased following Zanthoxylum coreanum, Ligularia fischeri, and Abies nephrolepis. The expression of cyclin E in Detroit 551 cells decreased with Ligularia fischeri and Abies nephrolepis treatment. The essential oils of Lindera obtusiloba, Zanthoxylum coreanum, and Ligularia fischeri did not produce a tendency for change in the expression level of cyclin E in Detroit 551 cell lines.

The protein expression levels of cyclin A, cyclin B, cyclin D, and cyclin E in the A549 and Detroit 551 cells at different concentrations of the essential oils are presented in Figs. 5 and 6. In the A549 cells, the protein expression levels of cyclin A, cyclin B, cyclin D, and cyclin E decreased in all essential oils except Ligularia fischeri in which the expression levels of cyclins A and B proteins increased. In the Detroit 551 cells, the protein expression levels of cyclin A, cyclin B, cyclin D, and cyclin E decreased after treatment with all essential oils except Ligularia fischeri for which the expression level of cyclin B increased and for Abies nephrolepis in which cyclin E protein expression increased. 
Table I. IC $_{50}$ values of essential oils in A549 cell line.

\begin{tabular}{lc}
\hline Essential oils & $\mathrm{IC}_{50}(\%, \mathrm{v} / \mathrm{v})$ \\
\hline Pinus densiflora for. multicaulis Uyeki & 0.1788 \\
Trifolium repens & 0.04198 \\
Ligularia fischeri & 0.4609 \\
Abies nephrolepis & 0.09788 \\
Illicium anisatum & 0.03975 \\
Zanthoxylum coreanum & 0.03877 \\
Abies koreana & 0.06288 \\
Lindera obtusiloba & 0.6570 \\
Chamaecyparis obtusa & 0.02112 \\
Pinus densiflora & 0.02078 \\
Magnolia kobus & 0.4322 \\
Picea koraiensis & 0.02695 \\
Picea abies & 0.08707 \\
Abies holophylla & 0.01065 \\
Platycladus orientalis & 0.03627 \\
\hline
\end{tabular}

As indicated by the increased expression levels of caspase-3, apoptosis is the cell-death mechanism associated with the essential oils of Zanthoxylum coreanum and Ligularia fischeri in the Detroit 551 cell line. As indicated by the decreased expression levels of cyclin A, cyclin B, cyclin D, and cyclin $\mathrm{E}$, the cell-death mechanism associated with the rest of the tested essential oils is cell-cycle arrest.

\section{Discussion}

A plant essential oil is a volatile natural compound obtained as a secondary product of the plant and is characterized by a strong smell (12). The components of a plant essential oil depend on the species of plant undergoing essential oil extraction and from which part of the plant the oil is extracted (17). Oils may be extracted from different parts of the plant, such as leaves, fruit peels, seeds, bark, wood, and flowers, and are usually obtained via hydro- or steam distillation processes. Essential oils are complex mixtures of volatile compounds produced by living organisms. and are isolated by physical means (compression and/or distillation) from part of whole plants of known taxonomic origin (19).

Biological properties of various essential oils have been described in several studies. In India, Trifolium repens is fed to livestock and considered a folk medicine against intestinal helminthic worms (4), Illicium anisatum cause severe inflammation of the kidneys, urinary tract, and digestive organs (5). A Lindera obtusiloba water extract inhibited mast-cell-derived allergic inflammation in vitro and in vivo, suggesting it may have possible application in allergic diseases such as allergic rhinitis, asthma and atopic dermatitis (20). Chamaecyparis obtuse and Pinus densiflora exhibited anti-inflammatory effects in an in vivo study (12). Picea abies has been used as a traditional Austrian medicine internally (as syrup or tea) and externally (for bathing, for inhalation, and as an ointment, resin application, or tea) for treatment of disorders of the respiratory tract, skin, locomotory system, and gastrointestinal tract, as well as for infection treatment (21). Although there is extensive usage
Table II. IC $\mathrm{I}_{50}$ values of essential oils in Detroit 551 cells.

\begin{tabular}{lc}
\hline Essential oils & $\mathrm{IC}_{50}(\%, \mathrm{v} / \mathrm{v})$ \\
\hline Pinus densiflora for. multicaulis Uyeki & 0.3112 \\
Trifolium repens & 0.4699 \\
Ligularia fischeri & 0.2497 \\
Abies nephrolepis & 0.1852 \\
Illicium anisatum & 0.4954 \\
Zanthoxylum coreanum & 0.1736 \\
Abies koreana & 0.17572 \\
Lindera obtusiloba & 0.6819 \\
Chamaecyparis obtusa & 0.2663 \\
Pinus densiflora & 0.3411 \\
Magnolia kobus & 0.04752 \\
Picea koraiensis & 0.01884 \\
Picea abies & 0.01019 \\
Abies holophylla & 0.1164 \\
Platycladus orientalis & 0.1797
\end{tabular}

of essential oils and some of their effects have been described, there is a lack of studies on the cytotoxic effects of essential oils and their mechanisms of action.

Determining the $\mathrm{IC}_{50}$ value is regarded as a standard when assessing the toxicity of chemical compounds. In this study, the $\mathrm{IC}_{50}$ value for each essential oil was calculated by using a CCK- 8 assay. At concentrations close to the oil's $\mathrm{IC}_{50}$ value, cell viability (as \%) was shown to be markedly decreased in both human lung cells (A549) and human skin cells (Detroit 551). Cytostatic effects, identified by determining $\mathrm{IC}_{50}$ values, of essential oils from Pinus densiflora for. multicaulis Uyeki, Trifolium repens, Ligularia fischeri, Abies nephrolepis, Illicium anisatum, Zanthoxylum coreanum, Abies koreana, Lindera obtusiloba, Chamaecyparis obtuse, Pinus densiflora, Magnolia kobus, Picea koraiensis, Picea abies, Abies holophylla, and Platycladus orientalis were identified in A549 human lung cells and Detroit 551 human skin cells. Furthermore, at the determined cytotoxicity levels, we examined the expression levels of marker genes and proteins (caspase-3, cyclin A, cyclin B, cyclin $\mathrm{D}$, cyclin E) to elucidate each oil's cytotoxic mechanism. Various mechanisms may be account for the reported cytotoxic effects of some essential oils or their constituents, including induction of cell death by apoptosis and/or necrosis, cell-cycle arrest, and loss of function of key organelles (4). Caspase-3 is required for some typical hallmarks of apoptosis and is indispensable for apoptotic chromatin condensation and DNA fragmentation in all cell types examined and is considered a cell-death marker gene. Thus, caspase- 3 is essential for certain processes associated with the dismantling of the cell and the formation of apoptotic bodies, but it may also function before, or at, the stage when commitment to loss of cell viability is made (22). In Detroit 551 cells, expression levels of caspase-3 increased under high concentration treatments of Zanthoxylum coreanum, and Ligularia fischeri indicating that cell death can occur via treatment by essential oils from Zanthoxylum coreanum and Ligularia fischeri. In contrast, under high concentration treatment of Lindera obtusiloba, Abies koreana, and Abies nephrolepis 

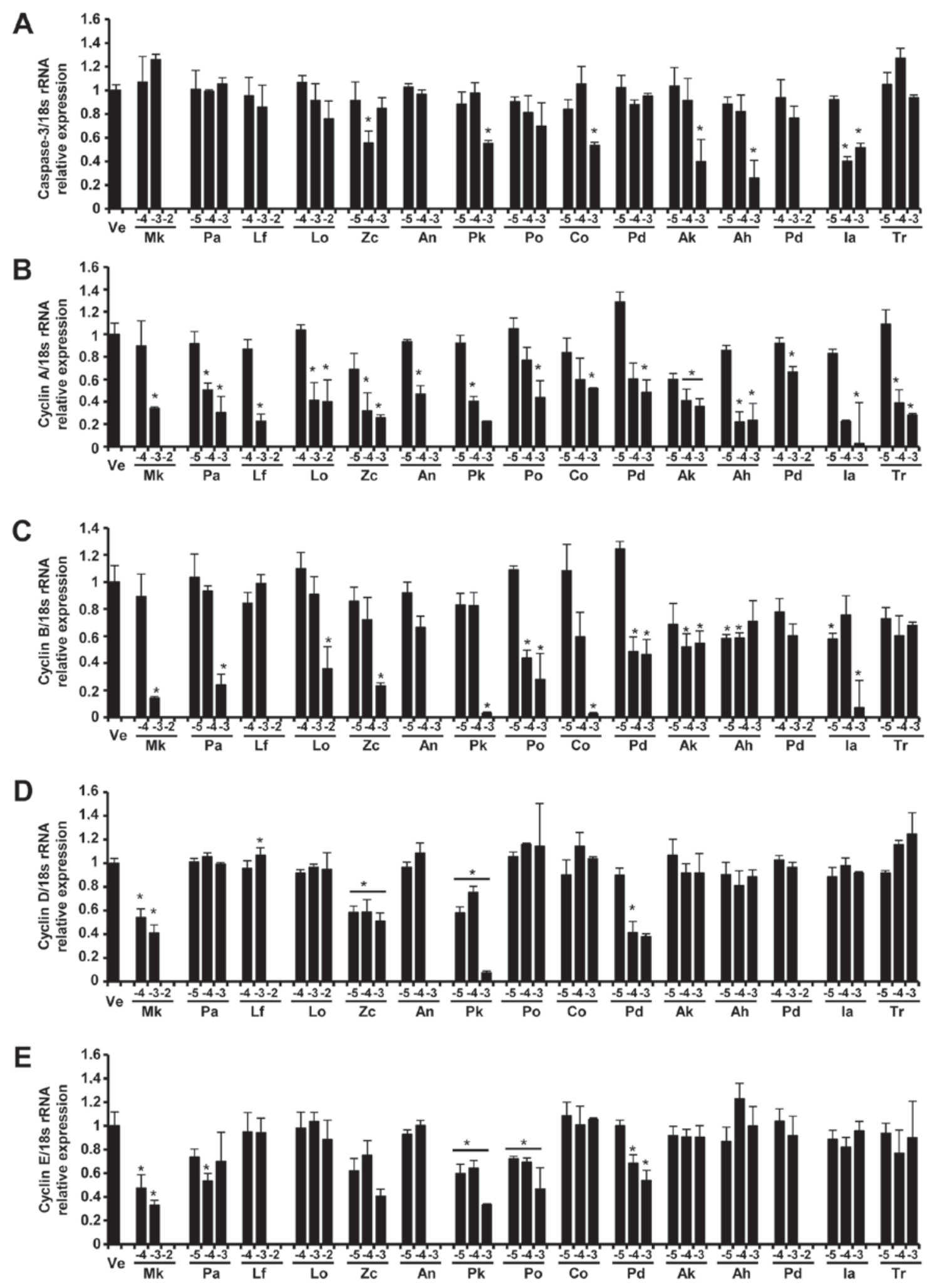

Figure 3. Expression of (A) caspase-3, (B) cyclin A, (C) cyclin B, (D) cyclin D and (E) cyclin E genes in A549 cells. The levels of caspase-3, cyclin A, cyclin B, cyclin D and cyclin E mRNA in the A549 cells of each group were determined via reverse transcription-quantitative PCR after treatment with three concentrations of essential oil. The control group was treated with vehicle (distilled water). Concentrations of $-5,-4,-3$ and -2 represented $10^{-5}, 10^{-4}, 10^{-3}$ and $10^{-2}$, respectively. Data are presented as the mean \pm standard deviation. ${ }^{*} \mathrm{P}<0.05$ vs. control.

essential oils, the expression levels of caspase-3 decreased. In A549 cells, expression levels of caspase-3 decreased under high concentration treatment by all oil samples. This suggests that the cytotoxicity of these oils in lung cell lines is due to inhibition of cell proliferation rather than to apoptosis. This suggests that there can be other mechanisms involved in essential oil-related cell death. Cell-cycle progression is controlled by the activities of complexes that are comprised of cyclins (A, B, D, E) bound to CDKs (20). The expression levels of cyclin A, cyclin B, cyclin $\mathrm{D}$, cyclin $\mathrm{E}$, which are cell-cycle regulation checkpoint 

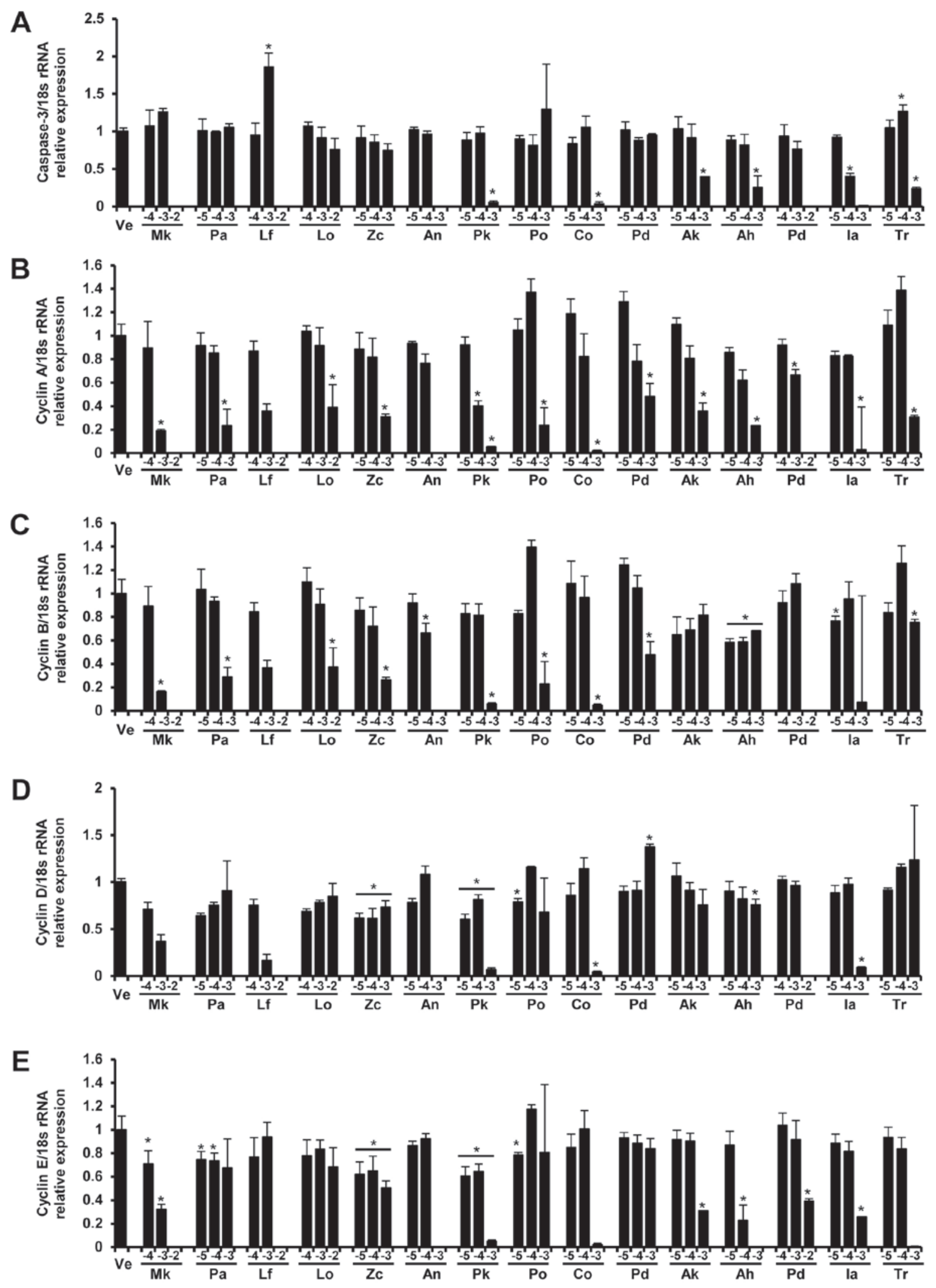

Figure 4. Expression levels of (A) caspase-3, (B) cyclin A, (C) cyclin B, (D) cyclin D and (E) cyclin E genes in Detroit 551 cells. The levels of caspase-3, cyclin $\mathrm{A}$, cyclin $\mathrm{B}$, cyclin D and cyclin E mRNA in the Detroit 551 cells of each group were determined by via reverse transcription-quantitative PCR after treatment with three concentrations of essential oil. The control group was treated with vehicle (distilled water). Concentrations of $-5,-4,-3$ and -2 represented $10^{-5}, 10^{-4}$, $10^{-3}$ and $10^{-2}$, respectively. Data are presented as the mean \pm standard deviation. ${ }^{*} \mathrm{P}<0.05$ vs. control.

markers for different cell-cycle stages, can be used to determine the timing of cell-cycle arrest. CyclinA is associated with the G1/S transition (the G1 checkpoint), cyclin B with the S phase progression (the intra-S phase checkpoint), cyclin D with the G2/M boundary (the G2/M checkpoint), and cyclin $\mathrm{E}$ with the spindle checkpoint at the transition from metaphase to anaphase 

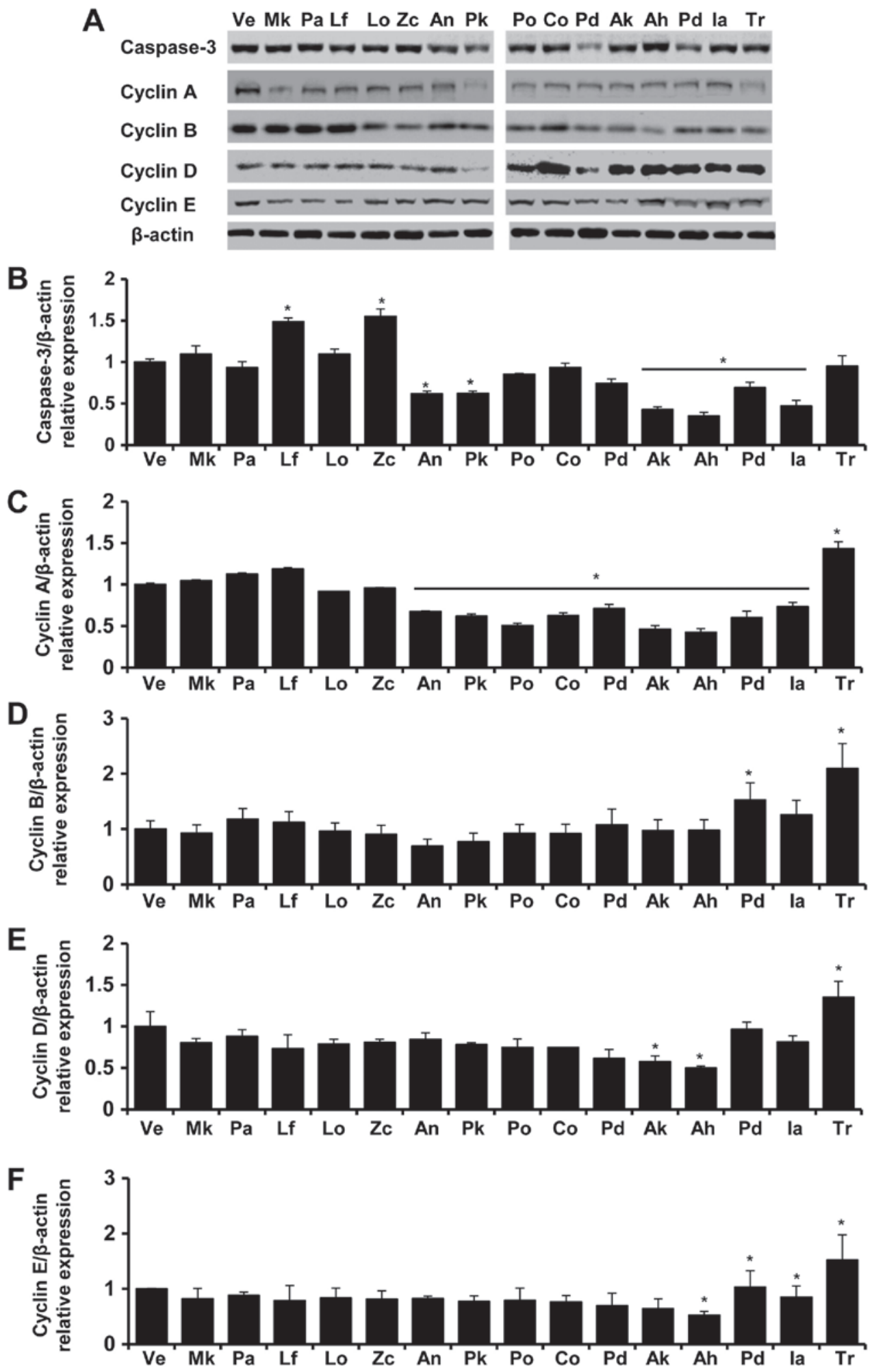

Figure 5. Expression of caspase-3, cyclin A, cyclin B, cyclin D and cyclin E proteins in A549 cells. Levels of caspase-3, cyclin A, cyclin B, cyclin D and cyclin E protein in the A549 cells of each group were determined via Western blot analysis after treatment with tessential oils (A). The protein expression level of Caspase-3 (B), Cyclin A (C), Cyclin B (D), Cyclin D (E), Cyclin E (F)/ $/$-actin in vehicle (Ve), Magnolia kobus (Mk), Picea abies (Pa), Ligularia fischeri (Lf), Lindera obtusiloba (Lo), Zanthoxylum coreanum (Zc), Abies nephrolepis (A.n), Picea koraiensis (Pk), Platycladus orientalis (Po), Chamaecyparis obtuse (Co), Pinus densiflora (Pd), Abies koreana (Ak), Abies holophylla (Ah), Pinus densiflora for. multicaulis Uyeki (Pd), Illicium anisatum (Ia), Trifolium repens (Tr) were presented. The control group was treated with vehicle (distilled water). Concentrations of $-5,-4,-3$ and -2 represented 10-5, 10-4, 10-3 and 10-2, respectively. Data are presented as the mean \pm standard deviation. $* \mathrm{P}<0.05$ vs. control. .

during mitosis. Checkpoint activation results either in cell death or improved cell survival, and deregulation of these cyclin-based critical signaling pathways may lead to the disruption of essential cellular functions (20). Therefore, decreases in the levels of specific cyclins can be used to indicate the specific phase of the cell cycle that is being inhibited by the oil being tested. There 


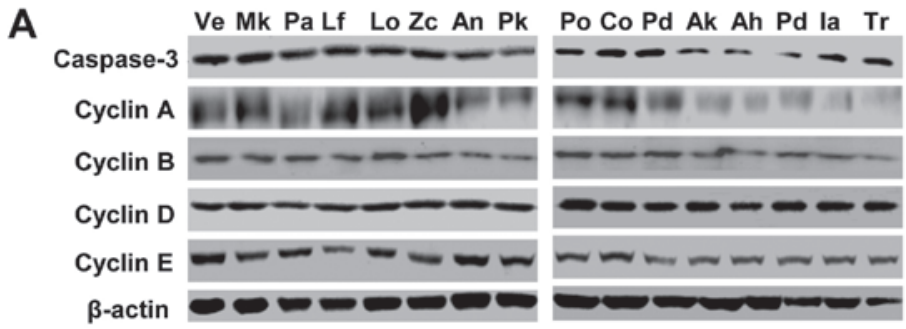

B

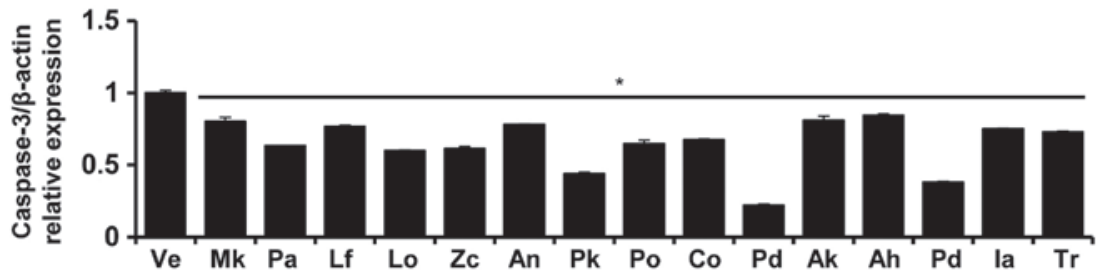

C

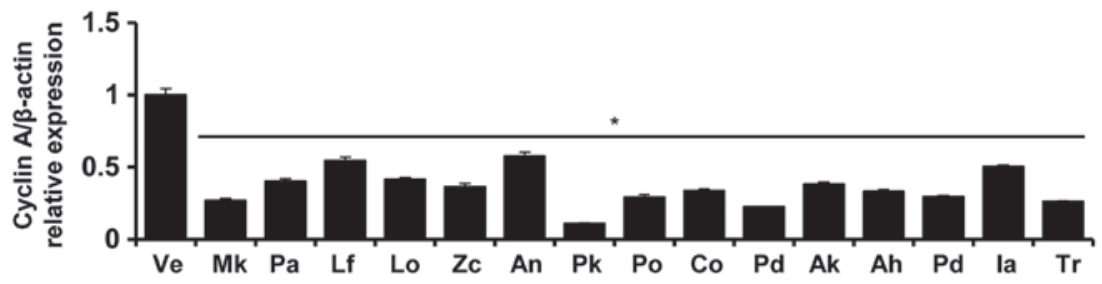

D

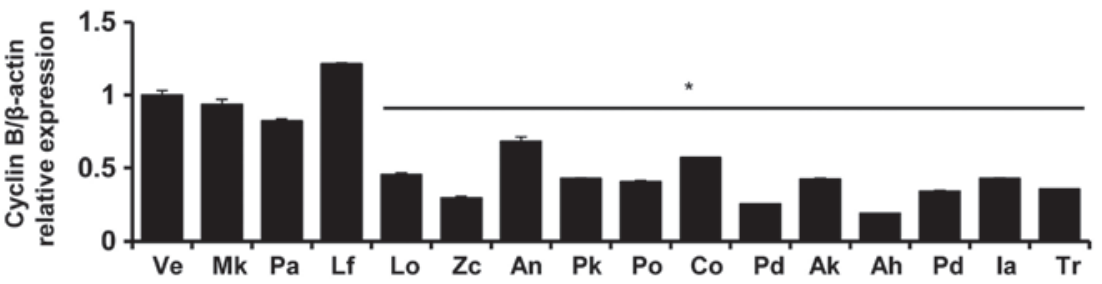

E

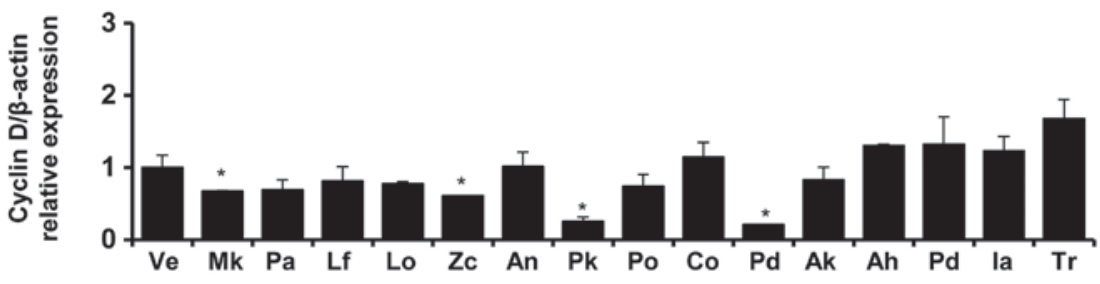

$\mathbf{F}$

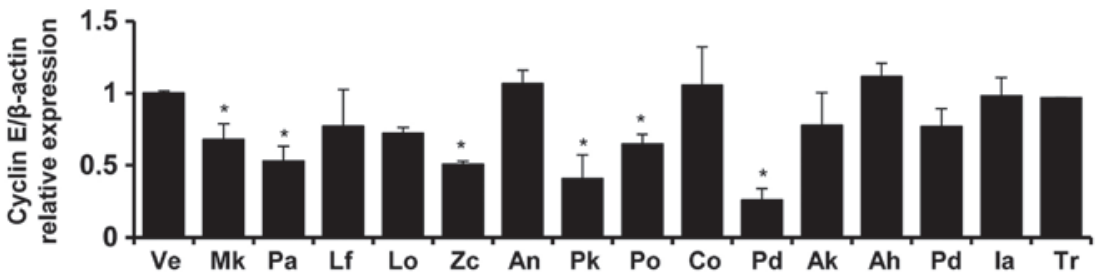

Figure 6. Expression of caspase-3, cyclin A, cyclin B, cyclin D and cyclin E proteins in Detroit 551 cells. Levels of caspase-3, cyclin A, cyclin B, cyclin D and cyclin E protein in the Detroit 551 cells of each group were determined via Western blot analysis after treatment with essential oils (A). The protein expression level of Caspase-3 (B), Cyclin A (C), Cyclin B (D), Cyclin D (E), Cyclin E (F)/ $\beta$-actin in vehicle (Ve), Magnolia kobus (Mk), Picea abies (Pa), Ligularia fischeri (Lf), Lindera obtusiloba (Lo), Zanthoxylum coreanum (Zc), Abies nephrolepis (A.n), Picea koraiensis (Pk), Platycladus orientalis (Po), Chamaecyparis obtuse (Co), Pinus densiflora (Pd), Abies koreana (Ak), Abies holophylla (Ah), Pinus densiflora for. multicaulis Uyeki (Pd), Illicium anisatum (Ia), Trifolium repens (Tr) were presented. The control group was treated with vehicle (distilled water). Concentrations of $-5,-4,-3$ and -2 represented 10-5, 10-4, 10-3 and 10-2, respectively. Data are presented as the mean \pm standard deviation. $* \mathrm{P}<0.05$ vs. control.

is little information on the medical and daily uses of some of the plant essential oils that were examined in this study. In our previous study, the essential oils of Chamaecyparis obtuse and Pinus densiflora have anti-inflammatory effects that differ for skin and lung cells. Illicium anisatum oil has toxic to proinflammatory effects dependent on its concentration (23). Therefore, determination of the appropriate concentration of a plant essential oil use is important when it is being used for clinical purposes.
In this study, we evaluated the cytotoxicity of several essential oils by performing CCK-8 assays and assessed the mechanism of their cytotoxic effect by conducting RT-qPCR of the cell-cycle-related genes, cyclin E, cyclin D, cyclin A, cyclin B, and caspase-3. Each essential oil had a distinctive $\mathrm{IC}_{50}$ value and they produced different expression patterns for cyclin E, cyclin D, cyclin A, cyclin B, caspase-3. Moreover, in the same essential oil, the $\mathrm{IC}_{50}$ values and expression patterns 
of the cell proliferation markers and the cell-death marker differed depending on the cell type being tested. Essential oils and their volatile constituents are used widely to prevent and treat human disease (22); however, medical use of a plant essential oil has the potential to cause adverse effects due to using an inappropriate dose of the oil. The lack of sufficiently convincing evidence regarding the effectiveness of a plant essential oil combined with its potential to cause adverse effects questions the usefulness of using this treatment modality under any conditions (24). Regardless, with insufficient evidence, plant essential oils can be effective in medical and daily use. For example, conditions such as atopic dermatitis or asthma can be alleviated with plant essential oils (12). In this study, to determine their cytotoxicity, we calculated the $\mathrm{IC}_{50}$ values for 15 plant essential oils from CCK-8 assay results and identified their cytotoxic mechanisms by examining the gene and protein expression levels of five marker genes (caspase-3, cyclin A, cyclin B, cyclin D, and cyclin E). The results support the conclusion that cell lines of human origin can be used to determine the safe concentration of a plant essential oil for skin and lung cell treatments (20). These results should provide users of these essential oils with guidelines for their clinically appropriate and safe use.

\section{Acknowledgements}

The authors give thanks to the ecologist Dr. Jae-Min Chung from The Korean National Institute for Taxonomical identifications of samples

\section{Funding}

The present study was supported by the National Institute of Forest Science funded by the Korean government (grant no. FP0700-2015-02).

\section{Availability of data and materials}

The datasets used and/or analyzed during the current study are available from the corresponding author on reasonable request.

\section{Authors' contributions}

C. A and E-B. J conceived the study, C. A and J-H. L performed and analyzed the experiments, YMY interpreted the data and finalized as well as proofread the manuscript. M-J. P, J-W. K and J. Y prepared the essential oil and analyzed the experiments. E-B. J supervised the study.

\section{Ethics approval and consent to participate}

Not applicable.

\section{Patient consent for publication}

Not applicable.

\section{Competing interests}

The authors declare that they have no competing interests.

\section{References}

1. Kumar Y, Prakash O, Tripathi H, Tandon S, Gupta MM, Rahman LU, Lal RK, Semwal M, Darokar MP and Khan F: AromaDb: A database of medicinal and aromatic Plant's aroma molecules with phytochemistry and therapeutic potentials. Front Plant Sci 9: 1081, 2018.

2. Diaz-Maroto MC, Diaz-Maroto Hidalgo IJ, Sanchez-Palomo E and Pérez-Coello MS: Volatile components and key odorants of fennel (Foeniculum vulgare Mill.) and thyme (Thymus vulgaris L.) oil extracts obtained by simultaneous distillation-extraction and supercritical fluid extraction. J Agric Food Chem 53: 5385-5389, 2005.

3. Huie CW: A review of modern sample-preparation techniques for the extraction and analysis of medicinal plants. Anal Bioanal Chem 373: 23-30, 2002.

4. Russo R, Corasaniti MT, Bagetta G and Morrone LA: Exploitation of cytotoxicity of some essential oils for translation in cancer therapy. Evid Based Complement Alternat Med 2015: 397821, 2015.

5. Manion CR and Widder RM: Essentials of essential oils. Am J Health Syst Pharm 74: e153-e162, 2017.

6. Cavanagh HM and Wilkinson JM: Biological activities of lavender essential oil. Phytother Res 16: 301-308, 2002.

7. Bakkali F, Averbeck S, Averbeck D and Idaomar M: Biological effects of essential oils-a review. Food Chem Toxicol 46: 446-475, 2008.

8. Israels ED and Israels LG: The cell cycle. Stem Cells 19: 88-91, 2001.

9. Wang XW, Zhan Q, Coursen JD, Khan MA, Kontny HU, Yu L, Hollander MC, O'Connor PM, Fornace AJ Jr and Harris CC: GADD45 induction of a G2/M cell cycle checkpoint. Proc Natl Acad Sci USA 96: 3706-3711, 1999.

10. Bertoli C, Skotheim JM and de Bruin RA: Control of cell cycle transcription during G1 and S phases. Nat Rev Mol Cell Biol 14: 518-528, 2013.

11. Vermeulen K, Van Bockstaele DR and Berneman ZN: The cell cycle: A review of regulation, deregulation and therapeutic targets in cancer. Cell Prolif 36: 131-149, 2003.

12. Donjerkovic D and Scott DW: Regulation of the G1 phase of the mammalian cell cycle. Cell Res 10: 1-16, 2000.

13. Kramer A, Mailand N, Lukas C, Syljuåsen RG, Wilkinson CJ, Nigg EA, Bartek J and Lukas J: Centrosome-associated Chk1 prevents premature activation of cyclin-B-Cdk1 kinase. Nat Cell Biol 6: 884-891, 2004.

14. Jänicke RU, Sprengart ML, Wati MR and Porter AG: Caspase-3 is required for DNA fragmentation and morphological changes associated with apoptosis. J Biol Chem 273: 9357-9360, 1998.

15. Li P, Nijhawan D and Wang X: Mitochondrial activation of apoptosis. Cell 116 (2 Suppl): S57-S59, 2004

16. Luo X, Budihardjo I, Zou H, Slaughter C and Wang X: Bid, a $\mathrm{Bcl} 2$ interacting protein, mediates cytochrome $\mathrm{c}$ release from mitochondria in response to activation of cell surface death receptors. Cell 94: 481-490, 1998.

17. Yang J,Liu X, Bhalla K, Kim CN, Ibrado AM, Cai J, Peng TI, Jones DP and Wang X: Prevention of apoptosis by Bcl-2: Release of cytochrome c from mitochondria blocked. Science 275: 1129-1132, 1997.

18. Porter AG and Jänicke RU: Emerging roles of caspase-3 in apoptosis. Cell Death Differ 6: 99-104, 1999.

19. Gurib-Fakim A: Medicinal plants: Traditions of yesterday and drugs of tomorrow. Mol Aspects Med 27: 1-93, 2006.

20. El-Aouar Filho RA, Nicolas A, De Paula Castro TL, Deplanche M, De Carvalho Azevedo VA, Goossens PL, Taieb F, Lina G, Le Loir Y and Berkova N: Heterogeneous family of cyclomodulins: Smart weapons that allow bacteria to hijack the eukaryotic cell cycle and promote infections. Front Cell Infect Microbiol 7: 208, 2017.

21. Barile FA and Cardona M: Acute cytotoxicity testing with cultured human lung and dermal cells. In Vitro Cell Dev Biol Anim 34: 631-635, 1998.

22. Edris AE: Pharmaceutical and therapeutic potentials of essential oils and their individual volatile constituents: A review. Phytother Res 21: 308-323, 2007.

23. Kim JY, Kim SS, Oh TH, Baik JS, Song G, Lee NH and Hyun CG: Chemical composition, antioxidant, anti-elastase, and anti-inflammatory activities of Illicium anisatum essential oil. Acta Pharm 59: 289-300, 2009.

24. Posadzki P, Alotaibi A and Ernst E: Adverse effects of aromatherapy: A systematic review of case reports and case series. Int J Risk Saf Med 24: 147-161, 2012. 